\title{
Fetal heart rate patterns in patients with thick meconium staining of amniotic fluid and its association with perinatal outcome
}

\author{
Dharna S. Desai*, Nandita Maitra, Purvi Patel
}

Department of Obstetrics and Gynecology, SSG Hospital, Medical College, Vadodara, Gujarat, India

Received: 26 January 2017

Accepted: 03 February 2017

\author{
*Correspondence: \\ Dr. Dharna S. Desai, \\ E-mail: dharnadesai2090@gmail.com
}

Copyright: () the author(s), publisher and licensee Medip Academy. This is an open-access article distributed under the terms of the Creative Commons Attribution Non-Commercial License, which permits unrestricted non-commercial use, distribution, and reproduction in any medium, provided the original work is properly cited.

\begin{abstract}
Background: This study assesses the role of abnormal fetal heart rate tracing patterns in patients with thick meconium staining of the amniotic fluid and its association with perinatal outcomes.

Methods: Prospective unmatched case-control study on 2 groups of 136 subjects each- cases had thick MSAF and controls had clear liquor with abnormal fetal heart rate tracings on cardiotocography.

Results: Gestational age (GA) >40 weeks, was found to have a significant association with MSAF ( $\mathrm{p}$ value 0.01556 CI 95\%). Premature Rupture of membranes at term (PROM) showed a significant association with MSAF with an OR of 2.25 (95\% CI 1.37, 3.7); Post datism had significantly higher odds for being a risk factor for MSAF with an OR (3.194) (CI 95\% 1.003-10.165). MSAF was not found to be significantly associated with abnormal trace on CTG. Neonatal morbidity (MAS, birth asphyxia, sepsis, HIE) had statistically higher odds in cases 1.669 (0.884-3.150) as compared to controls.

Conclusions: No particular cardio-tocograph pattern can be considered to have a poor prognostic value in the presence of thick MSAF and the decision to deliver and the mode of delivery should be based on the overall assessment and the stage and progress of labor. While management should be individualized, a higher Caesarean section rate in thick MSAF can be justified to ensure a better outcome for the neonate even in the presence of a normal CTG trace.
\end{abstract}

Keywords: Abnormal, Amniotic fluid, Meconium, Outcome, Trace

\section{INTRODUCTION}

The presence of meconium stained amniotic fluid is seen in $12-16 \%$ of deliveries. Meconium-stained amniotic fluid (MSAF) is common and it is associated with a fivefold increase in perinatal mortality as compared with lowrisk patients with clear amniotic fluid. ${ }^{1}$ It is a risk factor for neonatal meconium aspiration syndrome (MAS), sepsis, pulmonary disease and death, subsequent development of cerebral palsy in neonate; and amniotic fluid infection, chorioamnionitis, puerperal endometritis, and wound dehiscence or perineal lacerations in mother. Risk factors for MSAF include advanced gestational age at delivery, mode of delivery, increased duration of rupture of membranes (ROM), prolonged second stage of labor and intra-amniotic infection. ${ }^{2}$

The MSAF and its associations are very important determinants of maternal and perinatal morbidity and mortality; the fetus passes meconium in response to hypoxia and that meconium therefore signals fetal compromise. $^{3}$ Alternatively, in utero passage of meconium may represent normal gastrointestinal tract maturation under neuronal control. Meconium passage could also follow vagal stimulation from common but transient umbilical cord entrapment. Thick meconium has significantly greater risk of abnormal FHR tracings, a 1 and 5 minute APGAR score less than 7, a cord blood $\mathrm{pH}$ 
of less than 7.2, sepsis, need for $\mathrm{O} 2$ support and level III NICU admissions of babies. ${ }^{4}$

There are different opinions about the mode of delivery. Some experts believe that even if meconium is present in amniotic fluid, clinician may allow patients to labor in the presence of reassuring fetal heart rate and some prefer for immediate operative delivery. ${ }^{5}$ This study assesses the role of abnormal fetal heart rate tracing patterns in patients with thick meconium staining of the amniotic fluid and its association with perinatal outcomes.

\section{METHODS}

This was a prospective unmatched case-control study on 2 groups of 136 subjects each cases had thick MSAF and controls had clear liquor with abnormal fetal heart rate tracings on cardiotocography. Sample size was calculated using Epi-Info software, and using NICU admission rate as outcome to be studied in cases and controls. ${ }^{1}$ Fetal heart rate abnormalities were documented as per current recommendations. ${ }^{6}$ Cases and controls were selected on the basis of following inclusion criteria.

\section{Case selection}

- $\quad$ Presence of thick meconium in AF (pea-soup type) as determined by visual inspection, with or without fetal heart rate abnormality on CTG, in first or second stage of labor.

- Term Pregnancy (37 to 42 weeks' gestational age).

- $\quad$ Singleton pregnancy.

- Cephalic presentation.

- Known gestational age by LMP or First Trimester Ultrasound.

- No major congenital anomaly.

\section{Control selection}

One control per case was recruited with the following inclusion criteria:
- Clear amniotic fluid but with non-reassuring or pathological fetal heart rate pattern on CTG in first or second stage of labor.

- Term Pregnancy (37 to 42 weeks' gestational age).

- Singleton pregnancy.

- Cephalic presentation.

- Known Gestational age by LMP or First Trimester Ultrasound.

- No major congenital anomaly.

MSAF was managed as per the department labor ward protocol on fetal distress. Data relating to sociodemographic information, past obstetric history, associated medical conditions, index pregnancy characteristics, was collected for each case and control. The presence of MSAF was studied in relation to the following factors: Maternal age, parity, presence of maternal risk factors, fetal heart rate abnormality on CTG, premature rupture of membranes, spontaneous or induced labor, gestational age at delivery, oxytocin in labor, birth-weight, mode of delivery, Apgar score $<7$ at $5 \mathrm{~min}$, and admission to NICU, neonatal morbidity and mortality.

\section{Data entry and statistical analysis}

All data was entered into an excel sheet. Statistical analysis was performed using STATAIC version 13. Descriptive statistics used were Pearson's Chi-square with Fisher Exact test, Odd's ratio with 95\% confidence intervals and diagnostic tests of evaluation. A probability value of $<0.05$ was considered significant.

\section{RESULTS}

Table 1 shows the socio-demographic characteristics of cases and controls. The association with booking status, maternal age and parity was not significant. Gestational age (GA) >40 weeks, was found to have a significant association with MSAF ( $\mathrm{p}$ value 0.01556 CI 95\%).

Table 1: Socio-demographic characteristics of cases and controls.

\begin{tabular}{|c|c|c|c|c|}
\hline Parameters & & Cases $(n=136)$ & Control $(n=136)$ & Chi-square value (p-value) \\
\hline \multirow{2}{*}{ Booking status } & Booked & $70(51.47 \%)$ & $78(57.35 \%)$ & \multirow{2}{*}{0.2207} \\
\hline & Unbooked & $66(48.52 \%)$ & $58(42.64 \%)$ & \\
\hline \multirow{3}{*}{ Maternal age } & $<20$ & $2(1.47 \%)$ & $4(2.94 \%)$ & \multirow{3}{*}{0.6944} \\
\hline & $20-30$ & $127(93.38 \%)$ & $127(93.38 \%)$ & \\
\hline & $>30$ & $7(5.14 \%)$ & $5(3.67 \%)$ & \\
\hline \multirow{3}{*}{ Parity } & G1 & $88(64.70 \%)$ & $73(53.67 \%)$ & \multirow{3}{*}{0.06363} \\
\hline & G2-G5 & $47(34.55 \%)$ & $63(46.32 \%)$ & \\
\hline & $>\mathrm{G} 5$ & $1(0.735 \%)$ & 0 & \\
\hline \multirow{5}{*}{ Gestational age (weeks) } & $37-38$ & $16(11.76 \%)$ & $26(19.11 \%)$ & \multirow{5}{*}{0.01556} \\
\hline & $38-39$ & $33(24.26 \%)$ & $40(29.41 \%)$ & \\
\hline & $39-40$ & $34(25 \%)$ & $40(29.41 \%)$ & \\
\hline & $40-41$ & $38(27.94 \%)$ & $26(19.22 \%)$ & \\
\hline & $41-42$ & $15(11.02 \%)$ & $4(2.94 \%)$ & \\
\hline
\end{tabular}


Table 2: Relation of MSAF with presence of risk factors in cases and controls.

\begin{tabular}{|lllll|}
\hline Parameters & Cases $(\mathrm{n}=136)$ & Control $(\mathrm{n}=136)$ & OR $(95 \% \mathrm{CI})$ & (Chi-square) p-value \\
\hline Anemia & $26(19.11 \%)$ & $18(13.23 \%)$ & $1.549(0.805-2.982)$ & \multirow{2}{*}{0.03283} \\
\hline Oligohydromnios & $16(11.76 \%)$ & $28(20.58 \%)$ & $0.514(0.264-1.002)$ & \multirow{2}{*}{1} \\
\hline Pre-eclampsia & $49(36.02 \%)$ & $43(31.61 \%)$ & $1.218(0.736-2.015)$ & 1 \\
\hline Eclampsia & $3(2.20 \%)$ & $3(2.20 \%)$ & $1.000(0.198-5.044)$ & 0.001273 \\
\hline Abruptio-placenta & $4(2.94 \%)$ & $4(2.94 \%)$ & $1.000(0.245-4.083)$ & 0.03925 \\
\hline PROM & $67(49.26 \%)$ & $41(30.14 \%)$ & $2.250(1.369-3.699)$ & 0.4563 \\
\hline Post datism & $12(8.82 \%)$ & $4(2.94 \%)$ & $3.194(1.003-10.165)$ & $0.801(0.446-1.438)$ \\
\hline Previous C-section & $26(19.11 \%)$ & $31(22.79 \%)$ & & \\
\hline
\end{tabular}

Table 2 shows the relation of risk factors with MSAF. Anemia, oligohydramnios, preeclampsia, eclampsia, abruptio placentae and previous cesarean section did not show a significant association with MSAF. Premature Rupture of membranes at term (PROM) showed a significant association with MSAF with an OR of 2.25 (95\% CI 1.37, 3.7); Post datism had significantly higher odds for being a risk factor for MSAF with an OR (3.194) (CI 95\% 1.003- 10.165).

Table 3 shows the distribution of cardio-tocography patterns in cases and controls. Fourty two (30.88\%) subjects among cases had normal CTG, 37 (27.2\%) had suspicious trace and $57(41.91 \%)$ had pathological trace. Amongst the controls $19(13.97 \%)$ had suspicious trace and clear liquor and $117(86.02 \%)$ had pathological trace with clear liquor. More subjects among cases $72(52.94 \%)$ had normal baseline as compared to controls 43
(31.61\%). The sensitivity and specificity of baseline heart rate was $47.06(95 \% \mathrm{CI}, 44.20-61.55)$ and $31.62(95 \%$ CI, $23.92-40.14)$ respectively. A normal variability (>5) was seen in more cases $93(68.38 \%)$ as compared to controls 53 (38.97\%). Variable and late decelerations were seen in $34(25.0 \%)$ cases and $54(39.70 \%)$ controls. Accelerations were present in $92(67.64 \%)$ cases and 51 (37.5\%) controls.

Table 3: Relation of fetal distress with CTG in cases and controls.

\begin{tabular}{|lll|}
\hline Parameter & Cases $(n=136)$ & Control \\
\hline Normal & $42(30.88 \%)$ & 0 \\
\hline Suspicious & $37(27.20 \%)$ & $19(13.97 \%)$ \\
\hline Pathological & $57(41.91 \%)$ & $117(86.02 \%)$ \\
\hline
\end{tabular}

Table 4: Cardiotocography characteristics and performance indicators.

\begin{tabular}{|c|c|c|c|c|c|c|c|c|}
\hline Parameters & & Cases & Control & $\begin{array}{l}\text { Sensitivity } \\
(\%)(95 \% \\
\text { CI) }\end{array}$ & $\begin{array}{l}\text { Specificity } \\
(\%)(95 \% \\
\text { CI) }\end{array}$ & $\begin{array}{l}\text { Positive } \\
\text { predictive } \\
\text { value (\%) } \\
(95 \% \mathrm{CI})\end{array}$ & $\begin{array}{l}\text { Negative } \\
\text { predictive } \\
\text { value }(\%) \\
(95 \% \mathrm{CI})\end{array}$ & $\begin{array}{l}\text { Chi- } \\
\text { square } \\
\text { (p-value) }\end{array}$ \\
\hline \multirow{3}{*}{ Baseline } & $<110$ & $9(6.61 \%)$ & $17(12.5 \%)$ & \multirow{3}{*}{$\begin{array}{l}47.06 \\
(38.45- \\
55.80)\end{array}$} & \multirow{3}{*}{$\begin{array}{l}31.62 \\
(23.92- \\
40.14)\end{array}$} & \multirow{3}{*}{$\begin{array}{l}43.64 \\
(35.94- \\
51.56)\end{array}$} & \multirow{3}{*}{$\begin{array}{l}40.19 \\
(30.82- \\
50.11)\end{array}$} & \multirow{3}{*}{0.001401} \\
\hline & $110-160$ & $72(52.94 \%)$ & $43(31.61 \%)$ & & & & & \\
\hline & $>160$ & $55(40.44 \%)$ & $76(11.76 \%)$ & & & & & \\
\hline \multirow{3}{*}{ Variability } & $\geq 5$ & $93(68.38 \%)$ & $53(38.97 \%)$ & \multirow{3}{*}{$\begin{array}{l}31.62 \\
(23.92- \\
40.14)\end{array}$} & \multirow{3}{*}{$\begin{array}{l}38.97 \\
(30.73- \\
47.70)\end{array}$} & \multirow{3}{*}{$\begin{array}{l}34.13 \\
(25.92- \\
43.10)\end{array}$} & \multirow{3}{*}{$\begin{array}{l}36.30 \\
(28.51- \\
44.66)\end{array}$} & \multirow{3}{*}{$1.113 \mathrm{e}-06$} \\
\hline & $\begin{array}{l}2(<5 \text { for } \\
>40 \mathrm{~min} \text { to } \\
<90 \mathrm{~min})\end{array}$ & $42(30.88 \%)$ & $75(55.14 \%)$ & & & & & \\
\hline & $\begin{array}{l}3(<5) \text { for } \\
\text { more than } \\
90 \text { min. }\end{array}$ & $1(0.962 \%)$ & $8(5.88 \%)$ & & & & & \\
\hline \multirow{5}{*}{ Deceleration } & None & $95(69.85 \%)$ & $53(38.97 \%)$ & \multirow{5}{*}{$\begin{array}{l}23.53 \\
(16.68- \\
31.56)\end{array}$} & \multirow{5}{*}{$\begin{array}{l}39.71 \\
(31.42- \\
48.45)\end{array}$} & \multirow{5}{*}{$\begin{array}{l}28.07 \\
(20.06- \\
37.26)\end{array}$} & \multirow{5}{*}{$\begin{array}{l}34.18 \\
(26.83- \\
42.13)\end{array}$} & \multirow{5}{*}{$2.654 \mathrm{e}-07$} \\
\hline & Early & $9(6.61 \%)$ & $29(21.32 \%)$ & & & & & \\
\hline & Variable & $28(20.58 \%)$ & $52(38.23 \%)$ & & & & & \\
\hline & Late & $3(2.20 \%)$ & 0 & & & & & \\
\hline & Sinusoidal & $3(2.20 \%)$ & $2(1.47 \%)$ & & & & & \\
\hline \multirow[b]{2}{*}{ Acceleration } & Present & $92(67.64 \%)$ & $51(37.5 \%)$ & \multirow{2}{*}{$\begin{array}{l}32.35 \\
(24.59- \\
40.90)\end{array}$} & \multirow{2}{*}{$\begin{array}{l}37.50 \\
(29.35- \\
46.21)\end{array}$} & \multirow{2}{*}{$\begin{array}{l}34.11 \\
(25.99- \\
42.97)\end{array}$} & \multirow{2}{*}{$\begin{array}{l}35.66 \\
(27.84- \\
44.10)\end{array}$} & \multirow[b]{2}{*}{$6.405 \mathrm{e}-07$} \\
\hline & Absent & $44(32.35 \%)$ & $85(62.5 \%)$ & & & & & \\
\hline
\end{tabular}


Table 5A: Mode of delivery in cases and controls.

\begin{tabular}{|c|c|c|c|c|}
\hline Parameters & & Cases $(n=136)$ & Control $(n=136)$ & Chi-square (p-value) \\
\hline \multirow{3}{*}{ Spontaneous } & Vaginal delivery & $34(25 \%)$ & $35(25.73 \%)$ & \multirow{3}{*}{0.3611} \\
\hline & Instrumental delivery & $4(2.94 \%)$ & $2(1.47 \%)$ & \\
\hline & C- section & $70(51.47 \%)$ & $48(35.29 \%)$ & \\
\hline \multirow{3}{*}{ Induced } & Vaginal delivery & $8(5.88 \%)$ & $21(15.44 \%)$ & \multirow{3}{*}{0.09327} \\
\hline & Instrumental delivery & $4(2.94 \%)$ & $1(0.73 \%)$ & \\
\hline & C- section & $16(11.76 \%)$ & $29(21.32 \%)$ & \\
\hline
\end{tabular}

Table 5B: Type of cardio-tocograph with mode of delivery in cases and controls.

\begin{tabular}{|lllll|}
\hline \multirow{2}{*}{ Mode of delivery } & Vaginal delivery & \multicolumn{2}{c|}{ Caesarean section } & Control (n=77) \\
\hline Normal & Cases $(\mathbf{n = 5 0})$ & Control $(\mathbf{n = 5 9 )}$ & Cases (n=86) & 0 \\
\hline Suspicious & $13(26 \%)$ & 0 & $29(33.72 \%)$ & $4(5.19 \%)$ \\
\hline Pathological & $20(40 \%)$ & $15(25.42)$ & $17(19.76 \%)$ & $73(94.80 \%)$ \\
\hline
\end{tabular}

Table 6: Neonatal outcome in cases and controls.

\begin{tabular}{|lllll|}
\hline Outcomes & Cases & Control & OR $(95 \%$ CI & Chi-square (p-value) \\
\hline BW (grams) Mean and SD & $2743.31 \pm 428.849$ & $2756.6 \pm 418.05$ & $1.000(0.583-1.714)$ & 0.795517 \\
\hline APGAR score <7 at 1 min. & $80(58.82 \%)$ & $79(58.08 \%)$ & $1.031(0.636-1.670)$ & 0.9021 \\
\hline APGAR score <7 at 5 min. & $37(27.20 \%)$ & $35(25.73 \%)$ & $1.078(0.629-1.849)$ & 0.7834 \\
\hline NICU admission & $71(52.20 \%)$ & $43(31.61 \%)$ & $2.362(1.442-3.871)$ & 0.00058 \\
\hline Neonatal morbidity & $29(21.32 \%)$ & $19(13.97 \%)$ & $1.669(0.884-3.150)$ & 0.1117 \\
\hline Neonatal mortality & $14(10.29 \%)$ & $5(3.67 \%)$ & $3.007(1.052-8.592)$ & 0.03228 \\
\hline
\end{tabular}

Table 4 shows the mode of delivery and CTG abnormality among cases and controls. 109/272 subjects had vaginal delivery, of which 37 cases and 59 controls had abnormal CTG. Eighty-six cases (63.3\%) had caesarean delivery, of which 57 had abnormal trace as compared to $77(56.6 \%)$ subjects in the control group.

Table 5 shows the neonatal outcome in cases and controls. Mean birthweight, Apgar score $<7$ at 1 and 5 minutes were not significantly different in the two groups. Seventy-one $(52.2 \%)$ neonates in the cases group required NICU admission $>24$ hours as compared 43 $(31.61 \%)$ neonates in control group, with an OR 2.362 (1.442-3.871) and $\mathrm{p}$ value 0.00058 . Neonatal morbidity (MAS, birth asphyxia, sepsis, HIE) had statistically higher odds in cases $1.669(0.884-3.150)$ as compared to controls.

\section{DISCUSSION}

In this prospective, unmatched case control study, subjects with thick meconium in amniotic fluid (Cases) were compared to subjects with clear liquor and abnormal fetal heart rate tracings on cardiotocography (controls).

The study found that amongst maternal sociodemographic characteristics, only gestational age $>40$ weeks had a significant association with MSAF. A study by Fischer et al found that the incidence of MSAF linearly increased with GA. ${ }^{7}$ The rate of MSAF was $3.52 \%$ at $37-38$ versus $9.07 \%$ at $39-41(\mathrm{OR}=2.74$ [ 2.56 to 2.92, $\mathrm{P}<0.0001])$ and $14.37 \%$ at $42-43$ Weeks of Gestation $(\mathrm{OR}=4.60$ [4.03 to 5.26; $\mathrm{P}<0.001])$. Zhu L et al in 2003, stated that the percentage of parity, gestational week $\geq 42$ weeks and big birth weight were higher in meconium stained amniotic fluid group than that in normal amniotic fluid group $(\mathrm{P}<0.001) .{ }^{8}$ However, Osava $\mathrm{RH}$ did not find a correlation between gestational age more than 40 weeks and MSAF. ${ }^{9}$

In present study, maternal risk factors significantly associated with MSAF were premature rupture of membranes and post-datism. Contrary to expectation, factors such as anemia, preeclampsia and oligohydramnios were not significantly associated with MSAF. Studies differ in their observations on risk factors-Lee et al found that frequency of PROM was significantly lower in the MSAF group than in the clear amniotic fluid group. ${ }^{2}$ Gurubacharya SM, in a study based in Nepal found a higher association of PROM in subjects with MSAF. ${ }^{10}$ Kumari R et al found MSAF was more common in post term pregnancies and with intrauterine growth restriction (IUGR). ${ }^{3}$ Manohar et al in a study published in 2013 concluded that incidence of MSAF was more in pregnancy with crossed EDD (>40 weeks), oligohydroamnios, anemia and preeclampsia. ${ }^{11} \mathrm{In}$ 
a study by Balchin on 499,096 singleton births, independent predictors of meconium-stained AF included being black (odds ratio [OR] 8.4, 95\% CI 2.4-28.8), vaginal breech delivery (OR 4.7, 95\% CI 4.2-5.3), being South Asian (OR 3.3, 95\% CI 1.3-8.3), and being in an advancing week of gestation (OR 1.39, 95\% CI 1.381.4). ${ }^{12}$ Blackwell et al in 2002 noted that the frequency of MSAF at birth in term pregnancies was not related to amniotic fluid volume- oligohydramnios (16.7\%); decreased liquor (16.7\%); normal liquor (20.1\%); increased liquor $(24.4 \%)$, and polyhydramnios $(22.1 \%)$. The only factor associated with the occurrence of MSAF was increasing GA at delivery $(\mathrm{p}<0.01) .{ }^{13}$

present study did not show an increased association of abnormal fetal heart rate tracing with MSAF. All the parameters of a cardio-tocograph are likely to be normal in the presence of MSAF and therefore the decision to deliver and mode of delivery should be based on the overall assessment and progress of labor.

This observation is contrary to that of other studies on this subject. Vijaysree $\mathrm{M}$ et al, found that $6 \%$ of clear amniotic fluid had FHR abnormalities, whereas MSAF group had $34 \%$ FHR abnormalities. ${ }^{5}$ Odongo et al in a study on 77 subjects noted that the suspicious and pathologic tracings on CTG were increased in the meconium stained liquor group. ${ }^{14} \mathrm{Xu} \mathrm{H}$ in a 2009 study, found specific abnormalities that were associated with the risk of perinatal mortality and/or neonatal morbidity which included prolonged deceleratios (OR, 1.22;95\% CI, 1.02-1.48), severe variable decelerations (OR 1.08; 95\% CI, 1.00-1.16), bradycardia (OR, 2.49; 95\% CI, 1.02-6.11), and tachycardia (OR, 2.43; 95\% CI, 1.493.94). ${ }^{15}$ Grignaffini et al found that meconium-stained amniotic fluid was associated with lower $\mathrm{SpO} 2$ values only when fetal heart monitoring showed a "nonreassuring" pattern. ${ }^{16}$

Regarding mode of delivery, most studies have found a higher caesarean section rate. ${ }^{1,5,11}$ Shaikh EM found it was not uncommon for obstetricians to be more aggressive in labors with meconium stained amniotic fluid leading to higher caesarean section rate, which was $82 \%$ in their study. ${ }^{17}$ In contrast the caesarean section rate in the clear liquor group was $18 \%$ ( $82 \%$ vs $18 \% \mathrm{P}<0.05)$. Thus, the decision regarding mode of delivery demands individual clinical judgement, weighing the estimated time until vaginal delivery against the estimated time until the onset of metabolic acidosis.

Neonatal mortality and morbidity was noted to be significantly higher in the MSAF group. This finding is consistent with that of other studies. Chakraborty A et $\mathrm{al}^{18}$ found that babies born out of MSAF had significantly prolonged NICU admission and perinatal mortality than the clear amniotic fluid group. In multivariate analysis, Hiersh $\mathrm{L}$ et al found that MSAF was associated with increased respiratory morbidity (OR, 4.74; 95\% CI, 3.87-
5.82; $\mathrm{p}<0.001)$, and increased risk for short-term neonatal morbidity. ${ }^{19}$

This small study on 272 subjects, could not estimate the prevalence of MSAF in the hospital population due to the study design. The control group had only subjects with a suspicious or pathological trace and clear liquor; study did not compare normal cardio-tocograph patterns in the control group with that of MSAF group. The facility for fetal scalp blood sampling and estimation of cord blood $\mathrm{pH}$ are not available in the hospital and were not used in the study.

\section{CONCLUSION}

However, the study has demonstrated that MSAF is an important sign of fetal distress and adverse outcomes in terms of neonatal morbidity and mortality. No particular cardio-tocograph pattern can be considered to have a poor prognostic value in the presence of thick MSAF and the decision to deliver and the mode of delivery should be based on the overall assessment and the stage and progress of labor. While management should be individualized, a higher Caesarean section rate in thick MSAF can be justified to ensure a better outcome for the neonate even in the presence of a normal CTG trace.

\section{Funding: No funding sources}

Conflict of interest: None declared

Ethical approval: The study was approved by the Institutional Ethics Committee

\section{REFERENCES}

1. Mundhra R, Agarwal M. Fetal outcome in meconium stained deliveries. $\mathrm{J}$ of Clin Diagnost Res. 2013;7(12):2874-6.

2. Lee KA, Lee SM, Yang HJ, Park CW, Mazaki-Tovi $\mathrm{S}$. The frequency of meconium-stained amniotic fluid increases as a function of the duration of labor. J Matern Fetal Neonatal Med. 2011;24(7):880-5.

3. Kumari R, Srichand P, Shah SZ, Devrajani BR. Fetal outcome in patients with meconium stained liquor. J Pak Med Assoc. 2012;62(5):474-6.

4. Tayade $\mathrm{S}$. The significance of meconium stained amniotic fluid- a cross sectional study in a rural setup. Int J Bio Adv Res. (2012);03(12):861-6.

5. Vijayasree M, Geetha L, Shobankumar DVC, Murthy SGK. Study of maternal and fetal outcomes in parturients with meconium stained amniotic fluid at term gestation- role of intrapartum amnio infusion. Scholars J App Med Sci. 2014;2(2C):752-6.

6. Intrapartum Care NICE Clinical Guideline 55 September 2007.

7. Fischer C, Rybakowski C, Ferdynus C. A population-based study of meconium aspiration syndrome in neonates born between 37 and 43 weeks of gestation. Int J Pediatr. 2012;2012:1-7.

8. Zhu L, Wong F, Bai J. The epidemiology of meconium stained amniotic fluid on hospital basis. 
Zhongguo yi xue ke xue Yuan xue Bao. Acta Academiae Medicinae Sinicae.2003;25(1):63-5.

9. Osava, Ruth Hitomi. Meconium-stained amniotic fluid and maternal and neonatal factors associated. Rev. SaúdePública [online]. 2012;46(6):1023-9.

10. Gurubacharya SM, Rajbhandari S, Gurung R, Rai A, Mishra M, Sharma KR, et al. Risk factors and outcome of neonates born through meconium stained amniotic fluid in a tertiary hospital of Nepal. J Nepal Paediatr Soc. 2015;35(1):44-8.

11. Manohar R, Kavyashree G. Retrospective study of various maternal factors responsible for meconium stained amniotic fluid and its impact on perinatal outcome. Int J Recent Trends Sci Tech. 2013;1:12935 .

12. Balchin I, Whittaker JC, Lamont RF, Steer PJ. Maternal and fetal characteristics associated with meconium- stained amniotic fluid. Obstet Gynecol. 2011;117(4):828-35.

13. Blackwell SC, Wolfe HM, Redman ME, Hassan SS. Relationship between meconium staining and amniotic fluid volume in term pregnancies. Fetal diagn Ther. 2002;17(2):78-82.

14. Odongo BE, Ndavi PM, Gachuno OW, Sequeira E. Cardiotocography and perinatal outcome in women with and without meconium stained liquor. East Afr Med J. 201087(5):199-204.

15. Xu H, Mas-Calvet M, Wei SQ, Luo ZC, Fraser WD. Abnormal fetal heart rate tracing patterns in patients with thick meconium staining of the amniotic fluid: associations with perinatal outcomes. Am J Obstet Gynecol. 2009;200(3):283.e1-7.

16. Grignaffini A, Soncini E, Ronzoni E, Piazza E. Meconium-stained amniotic fluid and fetal oxygen saturation measured by pulse oximetry during labor. Acta Bio Medica Ateneo Parmense. 2004;75(1):4552.

17. Shaikh EM, Mehmood S. Neonatal outcome in meconium stained amniotic fluid-one year experience. J Pak Med Assoc. 2010;60(9):711-4.

18. Chakraborty A, Mitra P, Seth S, Das A . Study on risk factors of meconium stained amniotic fluid and comparison of pregnancy outcome in clear and meconium stained amniotic fluid in a tertiary hospital, Kolkata, India. Int J Biol Med Res. 2013;4(2):3084-7.

19. Hiersh L, Krispin E, Aviram A, Wiznitzer A. Effect of meconium-stained amniotic fluid on perinatal complications in low-risk pregnancies at term. Am J Perinatol. 2015;33(4):378-84.

Cite this article as: Desai DS, Maitra N, Patel P. Fetal heart rate patterns in patients with thick meconium staining of amniotic fluid and its association with perinatal outcome. Int J Reprod Contracept Obstet Gynecol 2017;6:1030-5. 